Trends in Nursing and Midwifery Research and the Need for Change in Complementary Therapy Research

by

Francis C Biley PhD MSc BNurs RMN RGN PGCE(FE) FETCert Senior Lecturer in Nursing.

University of Wales College of Medicine.

and

Dawn Freshwater Ba(Hons) RGN RNT

Senior Lecturer.

Homerton College Cambridge, School of Health Studies.

Address for correspondence:

Dr F.C. Biley

Senior Lecturer

School of Nursing Studies

University of Wales College of Medicine

Heath Park

Cardiff

CF4 4XN

Tel/fax:

Email:

0222743734 (work)

BILEY@cf.ac.uk

0222810895 (home)

February 1999 


\section{Trends in Nursing and Midwifery Research and the Need for Change in Complementary Therapy Research.}

In recent years there has been a change in nursing and midwifery research. Whilst many of the subjects being studied remain the same, nurses and midwives have started to employ a range of data collection methods that are relatively new to the profession. Predominantly quantitative research, which concentrates on reduction, objectivity, manipulation, categorisation, passivity, control, prediction, causality and generalisability (Munhall and Oiler, 1986), is starting to be replaced by other approaches perhaps more congruent with nursing, midwifery and caring. As Moody (1990) stated, "the 1980's ushered in an array of diverse, sophisticated research methods...” with other authors adding that "nursing is just beginning to authenticate new territory that incorporates a plurality of methods" (Nagle and Mitchell, 1991). The following is an exploration of the recent apparent shift away from an emphasis on quantitative research in nursing and midwifery towards the use of qualitative methods which emphasise a greater degree of individuality, humanism, participation and interaction. It is suggested that the traditional quantitative research paradigm still exists in the field of complementary therapy research and that the shift that has taken place in nursing and midwifery research also needs to be considered more seriously in the field of research in complementary therapies.

Some years ago, Brown et al (1984) identified that the amount of research being completed by nurses was increasing, that this research was becoming more sophisticated and was moving away from a predominantly quantitative approach using descriptive, exploratory or experimental design that developed as a result of 
early nurse scientists being trained by natural scientists (Streubert and Carpenter, 1995). Instead, qualitative approaches are beginning to be employed. A meta-analysis, performed by Jacobsen and Meininger (1985), found that the use of experimental design peaked in the mid 60's and declined during the 80's but even then only $46 \%$ of research was patient focused.

Given the nature of nursing and midwifery, qualitative methods are often now seen to be more appropriate (Gorenberg, 1983; Lather, 1986) and ontologically and epistemologically congruent (Parse, 1996) than the methods that have previously been used. Relatively recent key texts such as Behind the Screens (Lawler, 1991), The Illness Experience: Dimensions of Suffering (Morse and Johnson, 1991) and Inside Nursing (Street, 1992) that used, respectively, grounded theory and ethnomethodology; grounded theory; and critical ethnography research methods to explore matters of ultimate concern, bear witness to this.

There is probably a multitude of reasons for the move away from using the previously dominant quantitative paradigm approaches to the study of nursing and midwifery. In identifying four patterns of knowing in nursing, Carper (1978) highlighted that in addition to the empirical; nurses could also pay attention to aesthetic, moral and personal knowledge. In order to allow this, less emphasis needed to be placed on the "hard science" experimental design approach and more emphasis on different ways of knowing and on different forms of knowledge. Nurses were beginning to identify the “complexity of nursing knowledge” (Street, 1992) and that the concern of nursing was and is “complex human phenomena” (Moody, 1990), that often require differing 
methods of conducting nursing research. Nursing was being challenged to develop and utilise research methods as expansive as the subjects they study.

The reducing dependence on reductionistic approaches that often failed to acknowledge the existence or importance of personal and contextual factors could improve the much cited failure to implement research findings in practice (Bircumshaw, 1990). For example, if research is conducted in context and is emancipatory and relevant, then it is much more likely to succeed in bringing about change (Fay, 1987). With so many research results not being used and resulting in an ‘application gap’, nursing and midwifery research must look to methods that involve the personal and contextual experience of practitioners in the identification of research questions (Long, 1998). In addition, research that considers personal and contextual factors has the potential to facilitate transformation in all that engage in it, turning research into a sacred work. It follows then that idiographic research methods require a greater degree of personal involvement from the researcher in all phases of the research endeavour, challenging the notion of boundaries between research, practice and theory.

In recent years there has been a move away from the reductionistic medical models of nursing and midwifery towards a more holistic nursing and midwifery paradigm. In the era of holism, the appropriateness or adequacy of the traditional scientific mode of enquiry in nursing and midwifery has been increasingly questioned (Moccia, 1988; Newman, 1983; Parse, 1996). The same questions need to be asked when studying the effects of complementary therapies. However, it would appear as though research in the field of complementary therapies still needs to consider alternatives to the 
perceived randomised control trail 'gold standard'. Statements such as "the validity of much of the research is questionable, many of the findings being based on case studies and anecdotal evidence” (Cawthorn, 1995) run the risk of doing nothing more than devalue qualitative research and perpetuates the traditional and dated view of science that restricts the potential for knowledge development. Similarly, Ernst (1997), whilst acknowledging the potential contribution that qualitative research can make to our understanding of the effectiveness of complementary therapies, maintains that there is still a need for them to be evaluated using randomised controlled trails. Freshwater (1996) noted that complementary therapies in nursing were in danger of being disregarded due to a lack of scientific research. This assertion was based on a systematic review of the research literature on complementary therapies and concluded that much of the literature was either ignored or heavily criticised due to its questionable merit, for the simple reason that there was a lack of the use of randomised control trials.

In nursing and midwifery, as in complementary therapies, new and exciting methods of research are needed that are "congruent with the belief systems" (Parse, 1988). As Kuhn (1970) intimated, a radical view of phenomena apparent in a true paradigm generates new questions for study and new methods of investigation. Methodologies appropriate from the perspective of a traditional worldview are incapable of capturing the meaning of relationships, which are of critical importance in nursing, midwifery and complementary therapies. Internal states of spiritual and healing experiences rarely lend themselves to the Procrustean bed of external observation. New and alternative research strategies are needed for this purpose. 
The 1980's saw an explosion in the interest in nursing theory and more particularly, in testing the adequacy of nursing theory. Appropriate and adequate testing often required the development of new patterns of nursing research. Out of this movement, Paterson and Zderad (1976) developed a method of research they called phenomenological nursology that could be used to test their humanistic conceptual framework. In order to test Leininger's (1985) model of Cultural Care Diversity and Universality, an ethnonursing methodology was developed. Parse (1988) and Parse, Coyne and Smith (1985) further developed methods that could be used to test Parse's model of Man-Living-Health, now known as Human Becoming (Parse, 1992, 1995, 1998) and Newman developed her own research method based on her Theory of Health as Expanding Consciousness (Newman, 1994). Nurses who study the Martha Rogers’ Science of Unitary Human Beings (Rogers, 1970; 1990) have begun to develop methodologies specifically designed to explore the conceptual system. These methods include The Unitary Field Pattern Portrait Method (Butcher, 1994) and The Rogerian Process of Inquiry (Carboni, 1995). It has also been suggested that phenomenological approaches may be most appropriate for the study of the Science of Unitary Human Beings (Reeder, 1986) and morphogenic or ideographic methods have also been recommended (Cowling, 1986). Additional methodologies such as the Q-methodology (described by Dennis, 1986), feminist research (Hall and Stevens, 1991; MacPherson, 1983), photography (Highly and Ferentz, 1988) and recognising the importance of reflexivity (Porter, 1993), the narrative (Sandelowski, 1991) and heuristics (Parse, 1996) and hermeneutics (Koch, 1995; Parse, 1996) have been explored. 
The above approaches are consistent with the changing philosophies in nursing (Meleis, 1989; cited in Barrett, 1990) and may help reveal new insights if adopted by nurses and midwives who are researching aspects of complementary therapies. All such approaches honour ordinary human experience and are practised in the context of research. Complementary therapies demand the development of or the application of similar research methodologies. An imaginative science is required to envision the potential of complementary therapies in human experience as opposed to tidy reports. That is not to say that there is not a place for traditional science in nursing and midwifery, rather it is to affirm that research based on the art of nursing and midwifery is an equal contender in the development of nursing and midwifery knowledge.

Theorists are developing new methods of research which are consistent with their philosophical position. Changing philosophical and epistemological positions raises another major issue for nurses and midwives working as complementary therapists. That is, what should be researched? It is no longer acceptable for nurses to concentrate on studying nurses. We need to study nursing (not nurses) and midwifery (not midwives) and to acknowledge the role of practising nurses and midwives in this regard. Changing paradigms call for new approaches and methods for building knowledge. Bloom (1987) in The Closing of the American Mind warned of the dangers of "being closed to the emergent, the new, the manifestations of progress". Nurses and midwives would do well to heed this warning and, when performing research in complementary therapies, not be content with meaning diminishing methodologies but strive to reveal the myriad of entities embedded within their caring practice. 


\section{REFERENCES.}

BARRETT EAM (1990) Rogerian Patterns of Scientific Enquiry. In: Visions of Rogers' Science-Based Nursing, EAM Barrett (editor). National League for Nursing, New York.

BIRCUMSHAW D (1990) The utilization of research findings in clinical nursing practice. Journal of Advanced Nursing 15, 1272-1280.

BLOOM A (1987) The closing of the American Mind. Simon and Schuster, New York.

BROWN JS, TANNER CA and PADRICK KP (1984) Nursing's search for scientific knowledge. Nursing Research 33: 1, 26-32.

BUTCHER HK (1994) The unitary field pattern portrait method: Development of a research method for Rogers’ Science of Unitary Human Beings. In: Rogers Scientifc Art of Nursing Practice, M Madrid and EAM Barrett (editors). National League for Nursing, New York.

CARPER BA (1978) Fundamental Patterns of Knowing in Nursing. Advances in Nursing Science 1: 1, 13-23.

CAWTHORN A (1995) A review of the literature surrounding the research into aromatherapy. Complementary Therapies in Nursing and Midwifery 1: 4, 118-120. CARBONI JT (1995) A Rogerian Process of Inquiry. Nursing Science Quarterly 8: 1, 22-37.

COWLING WR (1986) The Science of Unitary Human Beings: Theoretical Issues, Methodological Challenges, and Research Realities. In: Explorations on Martha Rogers' Science of Unitary Human Beings, VM Malinski (editor). Appleton-CenturyCrofts, Connecticut. 
DENNIS KE (1986) Q methodology: relevance and application to nursing research. Advances in Nursing Science 8: 3, 6-17.

FAY, F. (1987) Critical Social Science. Polity Press, Cambridge

FRESHWATER, D. (1996) Complementary Therapies and Research in Nursing

Practice. Nursing Standard 10: 38, 43-45.

GORENBERG BE (1983) The Research Tradition of Nursing: An Emerging Issue. Nursing Research 32, 347-349.

HALL JM and STEVENS PE (1991) Rigour in feminist research. Advances in Nursing Science 13: 3, 16-29.

HIGHLY B and FERENTZ T (1988) Esthetic Inquiry. In: Paths to Knowledge: Innovative Research Methods for Nursing, B Sarter (editor). National League for Nursing, New York

HINSHAW A (1987) National Centre for Nursing Research Priorities. National Institutes of Health, Washington.

JACOBSEN BS and MEININGER JC (1985) The designs and methods of published nursing research: 1956-1983. Nursing Research 24, 89-92.

KOCH T (1995) Interpretive approaches in nursing research: the influence of Husserl and Heidegger. Journal of Advanced Nursing 21, 827-836.

KUHN TS (1970) The structure of scientific revolutions. University Press, Chicago. LATHER P (1986) Research as Praxis. Harvard Educational Review 56: 3, 257-277. LAWLER J (1991) Behind the Screens: Nursing, Somology, and the Problem of the Body. Churchill Livingstone, Edinburgh.

LEININGER M (1985) Qualitative research methods in nursing. Grune and Stratton, Florida. 
LoBIONDO-WOOD G and HABER J (1994) Nursing Research: Methods, Critical Appraisal, and Utilization, Third Edition. Mosby, St Louis.

LONG, A. F. (1998) Health services research - a radical approach to cross the research and development divide? In: Research and development for the NHS (2nd edition) M Baker and S Kirk (editors). Radcliffe Medical Press, Oxford.

MACPHERSON KL (1983) Feminist methods: a new paradigm for nursing research. Advances in Nursing Research 5: 2, 17-25.

MELEIS AI (1989) Nursing Science in the context of health: Panel discussion. Nurse Theorist Conference, May 12, Louisville, USA.

MOODY LE (1990) Advancing Nursing Science Through Research, Volume One. Sage, London.

MOCCIA P (1988) A critique of compromise: Beyond the methods debate. Advances in Nursing Science 10: 14, 1-10.

MORSE JM and JOHNSON JL, Editors (1991) The Illness Experience: Dimensions of Suffering. Sage, London.

MUNHALL PL and OILER CJ (1986) Nursing Research: A qualitative perspective. Appleton-Centruy-Crofts, Norwalk, CT.

NAGLE LM and MITCHELL GJ (1991) Theoretical diversity: Evolving paradigmatic issues in research and practice. Advances in Nursing Practice 14: 1, 17 25.

NEWMAN MA (1983) Editorial. Advances in Nursing Science 2, x-xi.

NEWMAN MA (1994) Health as expanding consciousness (2nd edition). National League for Nursing, New York.

PARSE RR (1988) Creating traditions: The art of putting it together. Nursing Science Quarterly 1, 45. 
PARSE RR, COYNE AB and SMITH MJ (1985) Nursing Research: Qualitative

Methods. Brady, Maryland.

PARSE RR (1992) Human Becoming: Parse’s theory of nursing. Nursing Science Quarterly 6: 1, 39-43.

PARSE RR (1995) The Human Becoming Theory. In: Illuminations: The Human Becoming Theory in Practice and Research, RR Parse (Editor). National League for Nursing, New York.

PARSE RR (1996) Building Knowledge Through Qualitative Research: The Road Less Travelled. Nursing Science Quarterly 9: 1, 10-16.

PARSE RR (1998) The Human Becoming School of Thought: A Perspective for Nurses and other Health Professionals. Sage, London.

PATERSON JG and ZDERAD LT (1976) Humanistic Nursing. National League for Nursing, New York.

PORTER S (1993) Nursing research conventions: objectivity or obfuscation? Journal of Advanced Nursing 18: 137-143.

REEDER F (1986) Basic Theoretical Research in the Conceptual System of Unitary Human Beings. In: Explorations on Martha Rogers' Science of Unitary Human Beings, VM Malinski (editor). Appleton-Century-Crofts, Connecticut.

ROGERS ME (1970) An Introduction to the Theoretical Basis of Nursing. FA Davis, Philadelphia.

ROGERS ME (1990) Nursing: Science of Unitary, Irreducible, Human Beings:

Update 1990. In: Visions of Rogers' Science-Based Nursing, EAM Barrett (editor). National League for Nursing, New York.

SANDELOWSKI M (1991) Telling Stories: Narrative Approaches in Qualitative Research. Image: Journal of Nursing Scholarship 23: 3, 161-166. 
STREET AF (1992) Inside Nursing: A Critical Ethnography of Clinical Nursing Practice. State University of New York Press, New York.

STREUBERT HJ and CARPENTER DR (1995) Qualitative Research in Nursing: Advancing the Humanistic Imperative. Lippincott, Philadelphia. 